\title{
Analysis of transcription factor OCT.1, OCT.2 and BOB.1 expression using tissue arrays in classical Hodgkin's lymphoma
}

\author{
Mónica García-Cosío ${ }^{1}$, Almudena Santón ${ }^{1}$, Paloma Martín ${ }^{1}$, Natalia Camarasa ${ }^{1}$, \\ Carlos Montalbán ${ }^{1}$, Juan F García ${ }^{2}$ and Carmen Bellas ${ }^{1}$ \\ ${ }^{1}$ Department of Pathology, Hospital Ramón y Cajal, Madrid, Spain and ${ }^{2}$ Centro Nacional de Investigaciones \\ Oncológicas, Madrid, Spain
}

\begin{abstract}
Hodgkin's lymphoma can be considered in most cases a B-cell lymphoma due to the presence of potentially functional immunoglobulin (Ig) gene rearrangements in the neoplastic cells. In contrast to lymphocytepredominant Hodgkin's lymphoma, Hodgkin/Reed-Sternberg (HRS) cells from classical Hodgkin's lymphoma have low frequency of B-cell marker expression and lack Ig light and Ig heavy messenger RNA. Recent studies have shown transcription machinery deficiency in Hodgkin's lymphoma caused by an absence of the transcription factors OCT.1, ОСТ.2 and/or BOB.1. By using the tissue microarray technique, we have performed an immunohistochemical study of OCT.1, OCT.2 and BOB.1 in 325 classical Hodgkin's lymphoma cases. The results have been correlated with the expression of the B-cell markers CD20, CD79a, B-cell-specific activator protein (BSAP) and MUM.1, the presence of Epstein-Barr virus and the histological subtype. The percentage of CD20 and CD79a positivity was low (18 and 18\%, respectively), whereas MUM.1 and BSAP were positive in the majority of cases. Considering the positive cases with independence of the intensity of staining, $62 \%$ of them expressed OCT.2, 59\% OCT.1 and 37\% BOB.1. Nevertheless, when we considered only the strongly positive cases, the results were similar to those previously described by others. No statistical association was found between the transcription factor expression, histological subtype and Epstein-Barr virus presence. To our knowledge, this is the largest series of classical Hodgkin's lymphoma cases in which the expression of transcription factors has been studied. We have found a notorious percentage of cases displaying weak positivity for OCT.2 and BOB.1 factors in HRS cells. We propose that other mechanisms different from the absence of transcription factors OCT.2 and BOB.1 might be involved in the control of Ig transcription and B lineage in classical Hodgkin's lymphoma.
\end{abstract}

Modern Pathology (2004) 17, 1531-1538, advance online publication, 16 July 2004; doi:10.1038/modpathol.3800227

Keywords: Hodgkin's lymphoma; transcription factors; OCT.2; BOB.1; MUM.1; BSAP; tissue microarray

Hodgkin's lymphoma is one of the most frequent lymphomas in western countries. There are two recognized forms: the classical Hodgkin's lymphoma form and the lymphocyte-predominant form. Morphologically, they are characterized by a few large tumour cells within a background of activated lymphocytes and mixed inflammatory cells. It has been demonstrated, by molecular studies, that Hodgkin's lymphoma is, in most cases, a B-cell lymphoma that originates from germinal centre ${ }^{1}$ neoplastic cells that escape from FAS-mediated apoptosis by an

Correspondence: Dr C Bellas, MD, PhD, Department of Pathology, Hospital Ramón y Cajal, Carretera de Colmenar KM.9100, 28034 Madrid, Spain.

E-mail: cbellas.hrc@salud.madrid.org

Received 23 April 2004; revised 28 May 2004; accepted 30 May 2004; published online 16 July 2004 unknown mechanism, ${ }^{2}$ probably involving $C$-FLIP overexpression. ${ }^{3}$ Neoplastic cells from classical and lymphocyte-predominant Hodgkin's lymphoma usually present potentially functional clonal immunoglobulin (Ig) gene rearrangements though carrying a high load of somatic mutations., ${ }^{1,2}$

What differentiates classical Hodgkin's lymphoma from lymphocyte-predominant Hodgkin's lymphoma is a low frequency of expression of B-cell-associated molecules (such as CD20, CD79a and J chain), and an absence of Ig light and Ig heavy messenger RNA (mRNA) ${ }^{4}$ in Hodgkin/Reed-Sternberg (HRS) cells. To explain this fact, several studies were performed. The first of them suggested crippling somatic mutations that would impede the Ig gene regulation, ${ }^{5,6}$ but further studies demonstrated that, in most cases, there were not such mutations and that the lack of Ig expression in classical Hodgkin's 
lymphoma was due to a transcription machinery disruption caused by a deficiency in transcription factors, as was confirmed by transfection in cellular lines. ${ }^{4,7,8}$ Mutations in the Ig-octamer-binding region $^{2}$ have finally been ruled out as the cause of the lack of B-specific gene expression. ${ }^{8}$

Transcription factors OCT.1 and OCT.2, and their coactivator BOB.1, are necessary for the octamerdependent transcription of Ig and other important lymphoid-specific genes of $\mathrm{B}$ cells. ${ }^{9-11}$ Also, the activity of the cotransduced Ig promoter can be restored by transfection with BOB.1 and OCT.2 and/ or OCT.1. ${ }^{7}$

OCT.1 is an ubiquitous factor present in a wide range of lymphoid and not lymphoid cell types. Studies on the expression of OCT.1 have demonstrated a high-level expression in pre-B cell lines. ${ }^{12,13}$ On the other hand, OCT.2 expression is restricted to B cells and neuronal cells,${ }^{14}$ and plays an important role in Ig promoter transactivation, as has been demonstrated by transfection experiments. ${ }^{15}$ They both participate in the control of important B-specific genes involved in proliferation and differentiation, ${ }^{16-20}$ such as Ig genes, CD20, CD79a and J chain. Transfection studies have demonstrated that OCT.1 can compensate the absence of OCT.2. ${ }^{21}$

Octamer functions are dependent on the presence of the B-cell-restricted coactivator BOB.1, which is a transcription factor necessary for B-cell development, inducing the formation of germinal centres. ${ }^{16,22,23}$

With the aim of evaluating the expression of transcription factors at the protein level in HRS cells in the largest series of cases reported until now, we performed an immunohistochemical study for OCT.1, OCT.2 and BOB.1 in 325 cases of classical Hodgkin's lymphoma, correlating the results with the expression of the B-cell markers CD20, CD79a, B-cell-specific activator protein (BSAP) and MUM.1, the presence of Epstein-Barr virus and the histological subtype. For this purpose, we used the recently developed tissue microarray technology that allows the simultaneous analysis of a large number of cases and whose feasibility in Hodgkin's lymphoma analysis has been demonstrated. ${ }^{24,25}$

\section{Materials and methods}

\section{Classical Hodgkin's Lymphoma Samples and Cell Lines}

The collaborating members of the Spanish Hodgkin's Lymphoma Study Group collected 355 cases of classical Hodgkin's lymphoma during the period between 1994 and 1998, of which 325 cases were suitable for this study (see below). Using standard tissue sections, according to the World Health Organization (WHO) classification, ${ }^{26}$ there were 184 nodular sclerosis, 112 mixed cellularity, 18 lymphocyte-rich, nine lymphocyte-depletion and two unclassificable classical Hodgkin's lymphomas. All patients were treated with standard polychemotherapeutic regimens with or without adjuvant radiotherapy.

Paraffin blocks were selected only on the basis of the availability of suitable formalin-fixed, paraffinembedded tissue (at least $1 \mathrm{~mm}$ thick).

Paraffin-embedded blocks from reactive lymphoid tissue and different B- and T-cell lymphoma samples were obtained from the Tissue Archives of Centro Nacional de Investigaciones Oncológicas (CNIO) Tumour Bank.

We also obtained five Hodgkin's lymphomaderived cell lines (L428, HDLM2, L540, KMH2 and HD-MY-Z) from the German Collection of Microorganisms and Cell Cultures (DSMZ, Braunschweigh, Germany).

\section{Tissue Microarrays Design}

Tissue Arrayer device (Beecher Instrument, Silver Spring, MD, USA) was used to construct the tissue microarrays in CNIO. ${ }^{24}$ Briefly, the richest areas of HRS cells were marked in the paraffin blocks. In each case, two selected 1-mm-diameter cores from two different areas, were included along with 43 different controls. Thus, five different tissue microarray blocks were constructed, each containing 187 cores excepting block number 5 that contained 176 cores.

External controls were provided by cell lines, a representation of reactive lymphoid tissue (10 samples, including tonsil, spleen and lymphadenitis) and 28 samples of the most frequent nonHodgkin's lymphomas of which two were cases of B-cell chronic lymphocytic leukaemia, two of follicular lymphoma, two of mantle cell lymphoma, two of diffuse large B-cell lymphoma, two of Burkitt's lymphoma, two of peripheral T-cell lymphoma and other two of anaplastic large-cell lymphoma. We used the previously referred cell lines, grown following standard protocols, fixed in formalin and included in paraffin as described. ${ }^{27}$ Tumour cells had to be identified in each of the two cylinders of a case to be included in the study.

\section{Immunohistochemistry}

Immunohistochemistry was performed as previously described. ${ }^{24}$ Tissue microarray blocks were sectioned with a thickness of $3 \mu \mathrm{m}$ and dried for $16 \mathrm{~h}$ at $56^{\circ} \mathrm{C}$ before being dewaxed in xylene and rehydrated through a graded ethanol series and later washed with phosphate-buffered saline. Antigen retrieval was achieved by heat treatment in a pressure cooker for $2 \mathrm{~min}$ in $10 \mathrm{mM}$ citrate buffer (pH 6.5). Before staining the sections, endogenous peroxidase was blocked. Immunohistochemical staining was performed on the sections using seven different antibodies: CD20 (L26, B cells; Dako), CD79a (JCB117, Dako), MUM.1 (ICSAT/M-17, Santa 
Cruz Biotechnology), BSAP (polyclonal, Santa Cruz Biotechnology), OCT.1 (12F11, Santa Cruz Biotechnology), OCT.2 (polyclonal, Santa Cruz Biotechno-logy) and BOB.1 (polyclonal, Santa Cruz Biotechnology). All of them were carried out in CNIO except BSAP that was performed in Ramón y Cajal Hospital. MUM.1, BSAP, OCT.1, OCT.2 and BOB.1 antibodies were used at 1:200, 1:250, 1:100, 1:500 and 1:7000 dilutions, respectively. After incubation, immunodetection was performed with the LSAB Visualization System (Dako, Glostrup, Denmark) using diaminobenzidine chromogen as substrate. Sections were counterstained with haematoxylin. Internal control was provided in each case by the reactivity of the accompanying lymphocytes, plasma cells and macrophages.

The pattern of staining was recorded as + (weak and focal positivity), ++ (intense positivity in most of cells, as strong as in normal and neoplastic germinal centre control cells) and - (completely absent), considering the expression in the nucleus of the neoplastic cells. All of the weak positive cases were associated to a focal pattern of staining.

The results were evaluated by two investigators (MGC and PMA) using uniform criteria. Identical results in each of the two cores were considered necessary to be suitable for the study.

\section{In Situ Hybridization of Epstein-Barr Virus-Encoded RNAs (EBERs)}

EBERs in situ hybridization was performed in CNIO. ${ }^{24}$ Tissue microarray sections were pretreated with proteinase $\mathrm{K}$ for $10 \mathrm{~min}$ at $37^{\circ} \mathrm{C}$, and then incubated with EBER PNA Probe/FITC (Dako) for $1.5 \mathrm{~h}$ at $55^{\circ} \mathrm{C}$ in a humid chamber and afterward washed with Stringent Wash Solution for $25 \mathrm{~min}$ at $55^{\circ} \mathrm{C}$ in a water bath with shaking. Detection was performed with antifluorescein isothiocyanate (antiFITC) antibody (clone DAK-FITC4, from Dako) diluted at 1:100. After incubation, immunodetection was performed with biotinylated antimouse immunoglobulins, followed by peroxidase-labelled streptavidin (LSAB Visualization System, Dako) with diaminobenzidine chromogen as substrate. Sections were counterstained with haematoxylin.

\section{Statistical Study}

The Pearson $\chi^{2}$ test and Fisher's exact test were used, where appropriate, to establish any association between the different markers included in the study. Differences were considered significant for values of $P<0.05$.

\section{Results}

The results of immunohistological studies on the tissue arrays, in the overall classical Hodgkin's lymphoma cases, for CD20, CD79a, OCT.1, OCT.2, BOB.1, BSAP, MUM.1 and EBERs are shown in Table 1 . The positivity range of the markers studied, considering the different histological subtypes except for the two nonclassificable classical Hodgkin's lymphoma cases are displayed in Tables 2-5.

CD20 and CD79a were found in a small percentage of cases (18 and 18\%, respectively). None of the lymphocyte depletion cases expressed CD20. Lymphocyte-rich classical Hodgkin's lymphoma was the subtype that showed more CD79a-positive cases $(43 \%)$, this association being significative.

Interestingly, BSAP was strongly expressed in all the studied cases (Figure 1), with independence of the histological subtype. MUM.1 positivity was frequently detected (98\% of cases), with a strong nuclear staining (Figure 2).

OCT.1 and OCT.2 were expressed in a notorious percentage of cases. Thus, when considering all the positive cases, with independence of the grade of staining, more cases expressed OCT.2 (Figures 3 and 4) than OCT.1 (62 vs 59\%). Variable staining for BOB.1 was seen in the $37 \%$ of cases (Figures 5 and 6). The histological subtype that showed a higher percentage of OCT.1, OCT.2 and BOB.1 positivity, was lymphocyte-rich, and the subtype that most frequently was negative for some of

Table 1 Total $\left(N^{*}=325\right)$

\begin{tabular}{lrrrrr}
\hline & $\mathrm{N}$ & ++ & + & - & $\%+$ \\
\hline CD20 & 305 & - & 55 & 250 & 18 \\
CD79a & 258 & - & 46 & 212 & 18 \\
PAX.5 & 273 & 62 & 211 & 0 & 100 \\
MUM.1 & 288 & 120 & 161 & 7 & 98 \\
OCT.1 & 323 & 35 & 154 & 134 & 59 \\
OCT.2 & 323 & - & 200 & 123 & 62 \\
BOB-1 & 304 & 49 & 64 & 191 & 37
\end{tabular}

CD20, CD79a, BSAP, MUM.1, OCT.1, OCT.2 and BOB.1 expression in overall classical Hodgkin's lymphoma. $N^{*}$ : total number of cases; $N$ : number of cases available; ++: strongly positive cases; +: weakly positive cases; -: negative cases; \%+: percentage (rounded) of overall positive cases.

Table 2 Nodular sclerosis $\left(N^{*}=184\right)$

\begin{tabular}{lrrrrr}
\hline & $\mathrm{N}$ & ++ & + & - & $\%+$ \\
\hline CD20 & 171 & - & 22 & 149 & 13 \\
CD79a & 141 & - & 19 & 122 & 13 \\
PAX.5 & 153 & 40 & 113 & 0 & 100 \\
MUM.1 & 162 & 74 & 83 & 5 & 97 \\
OCT.1 & 182 & 14 & 83 & 85 & 53 \\
OCT.2 & 182 & - & 111 & 71 & 61 \\
BOB.1 & 173 & 27 & 40 & 106 & 39 \\
\hline
\end{tabular}

Expression of all the studied markers in the different histological classical Hodgkin's lymphoma subtypes, respectively. $N^{*}$ : total number of cases; $N$ : number of cases available; ++: strongly positive cases; +: weakly positive cases; -: negative cases; \%+: percentage (rounded) of overall positive cases. 
Table 3 Mixed cellularity $\left(N^{*}=112\right)$

\begin{tabular}{lrrrrr}
\hline & $\mathrm{N}$ & ++ & + & - & $\%+$ \\
\hline CD20 & 110 & - & 29 & 81 & 26 \\
CD79a & 95 & - & 19 & 76 & 20 \\
PAX.5 & 94 & 17 & 77 & 0 & 100 \\
MUM.1 & 99 & 36 & 61 & 2 & 98 \\
OCT.1 & 112 & 20 & 53 & 42 & 65 \\
OCT.2 & 112 & - & 70 & 42 & 63 \\
BOB.1 & 104 & 15 & 19 & 70 & 33 \\
\hline
\end{tabular}

See footnote of Table 2.

Table 4 Lymphocyte rich $\left(N^{*}=18\right)$

\begin{tabular}{lrrrrr}
\hline & $\mathrm{N}$ & ++ & + & - & $\%+$ \\
\hline CD20 & 15 & - & 4 & 11 & 27 \\
CD79a & 14 & - & 6 & 8 & 43 \\
PAX.5 & 15 & 1 & 14 & 0 & 100 \\
MUM.1 & 17 & 4 & 13 & 0 & 100 \\
OCT.1 & 18 & 1 & 12 & 5 & 72 \\
OCT.2 & 18 & - & 13 & 5 & 72 \\
BOB.1 & 16 & 5 & 3 & 8 & 50 \\
\hline
\end{tabular}

See footnote of Table 2.

Table 5 Lymphocyte depletion $\left(N^{*}=9\right)$

\begin{tabular}{lllllr}
\hline & $\mathrm{N}$ & ++ & + & - & $\%+$ \\
\hline CD20 & 8 & - & - & 8 & 0 \\
CD79a & 8 & - & 2 & 6 & 25 \\
PAX.5 & 9 & 3 & 6 & 0 & 100 \\
MUM.1 & 9 & 5 & 4 & 0 & 100 \\
OCT.1 & 9 & 0 & 5 & 4 & 56 \\
OCT.2 & 9 & 0 & 6 & 3 & 67 \\
BOB.1 & 9 & 1 & 2 & 6 & 33 \\
\hline
\end{tabular}

See footnote of Table 2.

these factors, was nodular sclerosis. There was not any statistical association between the histological subtype and OCT.1, OCT.2 and BOB.1 expression.

Taking into account only the strongly positive cases $(++)$, the percentage of transcription factors positivity was much lower: OCT.1: 11\%, BOB.1: 16\%, OCT.2: $0 \%$ cases. There were no cases strongly positive for OCT.2 and BOB.1 simultaneously, and only $2 \%$ of cases were strongly positive for OCT.1 and BOB.1.

We found a direct association between OCT.2 and BOB.1 expression, regardless of the grade of positivity, OCT.2 expression was also statistically associated with all the B markers studied, excepting MUM.1.

Finally, in situ hybridization for EBERs was positive in $39 \%$ of cases, being mixed cellularity the subtype that more frequently showed the presence of Epstein-Barr virus (68\%) (Table 6). There was not any statistical association between

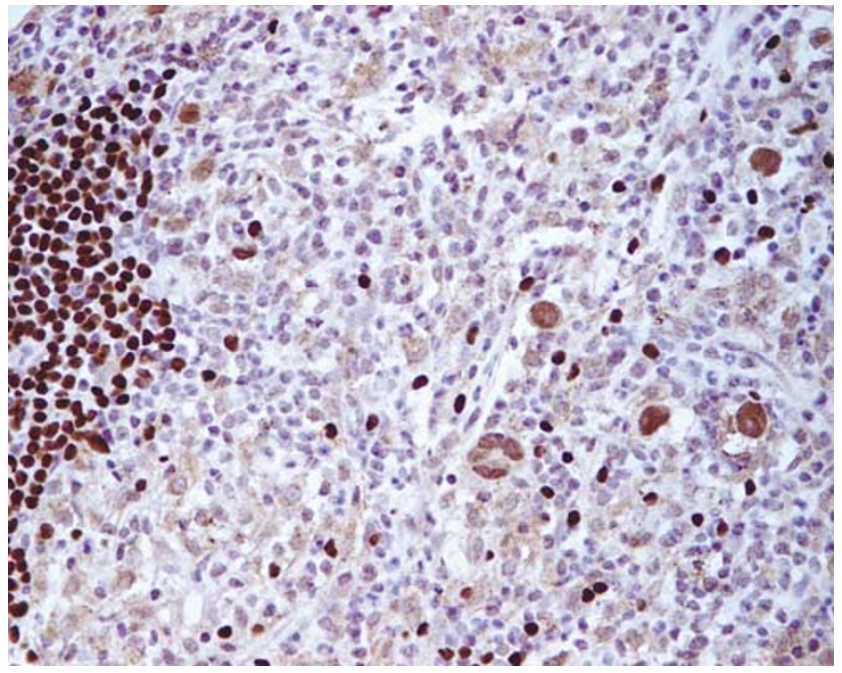

Figure 1 BSAP expression. Intense staining in nucleus of all HRS cells $(\times 400)$

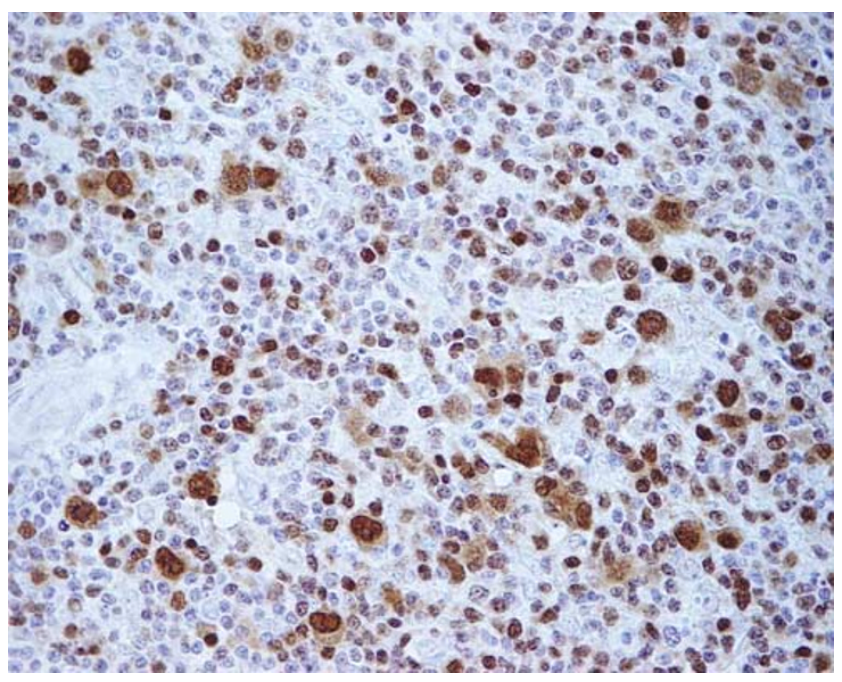

Figure 2 MUM.1 expression. Intense staining in nucleus of all HRS cells $(\times 400)$.

Epstein-Barr virus presence and transcription factor positivity.

\section{Discussion}

It is already known that HRS cells are often lack in expression of several B lineage markers, such as CD20, CD79a, OCT.2 and BOB.1..$^{4,7,8,28-30}$ In order to assess what previous studies have suggested about the lack of expression of transcription factors in classical Hodgkin's lymphoma, we performed an immunohistochemical analysis of OCT.1, OCT.2 and BOB. 1 in 325 cases, using the tissue microarray technique and correlating the results to the histological subtype, B-cell marker expression, and Epstein-Barr virus presence. We decided to study the transcription factors on the neoplastic cells at 


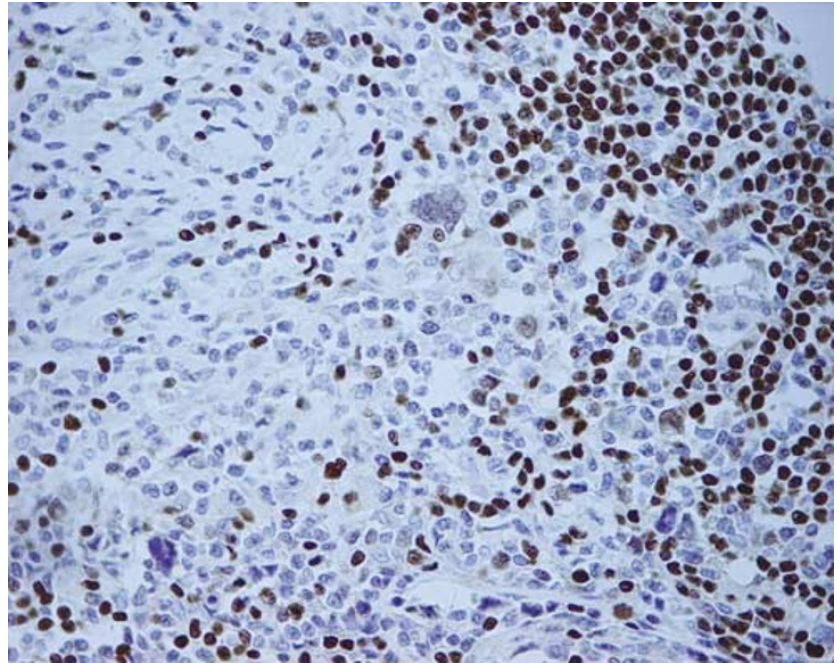

Figure 3 OCT.2 expression. All positive cases displayed a weak labelling as compared to normal B cells $(\times 400)$.

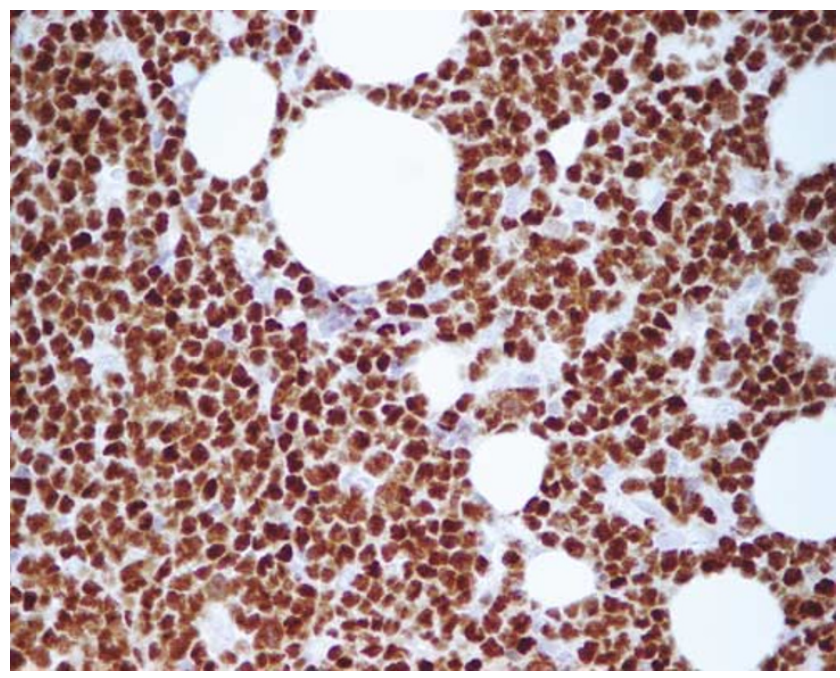

Figure 4 OCT.2 expression. Strong labelling in a non-Hodgkin's lymphoma control case $(\times 400)$.

the protein level because it might be more representative of their function than at the molecular level $^{28,31}$ and because there are few immunohistochemical studies including a large series of cases.

The reviewed studies about the expression of transcription factors are based, mostly, on cellular lines and do not specify clearly the intensity of the positivity. ${ }^{4,7,8}$ In our study, when only the strongly positive cases were considered, independently from the histological subtype, no cases strongly expressing OCT.2 were found. The frequency of strong OCT.1 and BOB.1 positivity was poor and even lower if their simultaneous expression was analysed, as has been described elsewhere. Conversely, when we analysed our cases, with independence of the intensity of the staining, the percentage of

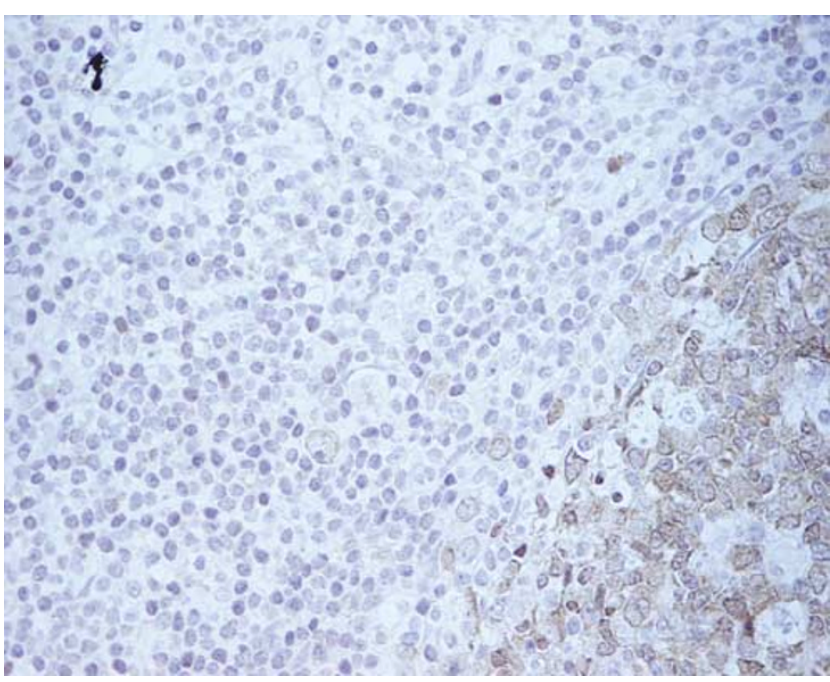

Figure 5 BOB.1 expression. A case of weak labelling in the nucleus of several, but not all, HRS cells $(\times 400)$.

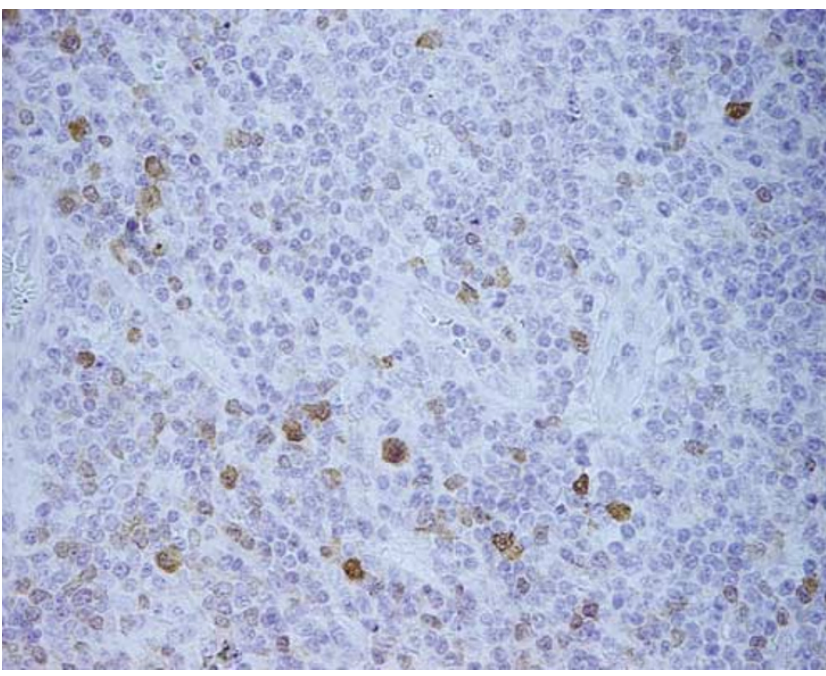

Figure 6 Strong BOB.1 expression in contrast to Figure 5.

Table 6 In situ hybridization for EBERs

\begin{tabular}{lrrrr}
\hline & N & Positive & Negative & $\%$ P \\
\hline$N^{*}$ & 301 & 117 & 185 & 39 \\
NS & 167 & 33 & 134 & 20 \\
MC & 108 & 73 & 35 & 68 \\
LR & 17 & 7 & 10 & 41 \\
LD & 9 & 4 & 5 & 44 \\
\hline
\end{tabular}

EBERs positivity in the overall and in the different histological classical Hodgkin's lymphoma subtypes respectively. $N^{*}$ : total number of cases studied; $N$ : number of cases; $\% P$ : rounded percentage of positive cases; NS: nodular sclerosis; MC: mixed cellularity; LR: lymphocyte rich; LD: lymphocyte depletion.

expression was much higher than that described before: $62 \%$ for OCT.2, $59 \%$ for OCT.1 and $37 \%$ for BOB.1. Similarly, OCT.1, OCT.2, and BOB.1 
expression without immunoglobulin production have been described recently by Pileri et $a l^{32}$ in a set of primary mediastinal B-cell lymphomas.

We did not find any significant association between OCT.1, OCT.2 and BOB.1 expression and the histological subtype, although the higher incidence of positivity of these markers in the lymphocyte-rich cases is notorious. This finding corroborates what previous studies have suggested about the fact that lymphocyte-rich classical Hodgkin's lymphoma might be more closely related to lymphocyte-predominant Hodgkin's lymphoma ${ }^{30}$ than to the other classical subtypes or that it could be in between classical and lymphocyte-predominant Hodgkin's lymphoma. ${ }^{33}$ From the 325 analysed cases, only a low percentage of them, less than expected, expressed CD20 and CD79a. This finding could be related to the use of tissue microarrays instead of whole sections, since the expression of these two markers is of varied intensities and present on a minority of the neoplastic cells. The significant association $(P<0.05)$ between the weak signal of OCT.2 and the expression of the B markers suggests the existence of a common B lineage downregulating factor.

BSAP is a transcription factor encoded by PAX.5 gene, involved in the establishment and the maintenance of B-cell identity. ${ }^{29,34}$ It is expressed in all B-cell stages of development from the pro-B-cell stage to the stage previous to plasma cell, where it is downregulated. ${ }^{35}$ Previous studies ${ }^{35-37}$ found a frequent BSAP expression in the HRS cells of classical Hodgkin's lymphoma. The percentage of BSAP positivity, in our cases, was of nearly $100 \%$, which provides an evidence for the B-cell origin of this disease. Considering that PAX.5 regulates CD20, CD79a and OCT.2 expression, the low positivity rate of these markers found in our study is surprising. In order to explain a functional defect in BSAP protein of HRS cells, some studies have been attempted in search for mutations in PAX.5 gene, ${ }^{29}$ but the absence of such mutations points to a defect of other essential factors in the control of B lineage of classical Hodgkin's lymphoma. Most of our cases expressed MUM.1, a transcription factor that belongs to the interferon regulatory factor family (IRF). ${ }^{38}$ It has been demonstrated that MUM.1 is expressed in the final step of intragerminal centre Bcell differentiation and in subsequent steps of B-cell maturation. ${ }^{39-41}$ The high frequency of expression of MUM.1 in the HRS cells of classical Hodgkin's lymphoma in our cases, and in reported series, ${ }^{38}$ suggests a similar phenotype between plasma cells and HRS cells, although the presence of BSAP expression in the latter is inconsistent with a final stage of differentiation that is seen in plasma cells.

Epstein-Barr virus presence was demonstrated by in situ hybridization in a considerable number of our cases (39\%), although we did not find any significative association with the expression of transcription factors. An association between the presence of Epstein-Barr virus and a decrease in the levels of the transcription factors that regulate B-cell lineage in experimental studies has been observed, ${ }^{42,43}$ but more studies are necessary to determine the role of Epstein-Barr virus in Ig gene expression.

In conclusion, the lack of strong labelling for transcription factors OCT.1, OCT.2 and BOB.1 in neoplastic cells of classical Hodgkin's lymphoma could explain, in part, the absence of Ig expression and $\mathrm{B}$ phenotype of these types of lymphomas in spite of the presence of potentially functional rearrangements of Ig genes. Nevertheless, the BSAP and MUM.1 simultaneous presence in most of our cases, and the weak expression of OCT.1, OCT.2 and BOB. 1 in a notorious percentage of HRS cells, may support the hypothesis that other mechanisms could be involved in Ig gene transcription and B lineage control of classical Hodgkin's lymphoma.

\section{Acknowledgements}

This report was supported in part by Grant CAM No. 08.1/0042.2/2001 from Consejería de Educación y Cultura de la Comunidad de Madrid. We thank Dr Argüelles for her critical review and Ms Carolina Herranz for her excellent technical assistance.

\section{References}

1 Marafioti T, Hummel M, Foss HD, et al. Hodgkin and Reed-Sternberg cells represent an expansion of a single clone originating from a germinal center B-cell with functional immunoglobulin gene rearrangements but defective immunoglobulin transcription. Blood 2000;95:1443-1450.

2 Jox A, Zander T, Küppers R, et al. Somatic mutations within the untranslated regions of rearranged Ig genes in a case of classical Hodgkin's disease as a potential cause for the absence of Ig in the lymphoma cells. Blood 1999;93:3964-3972.

3 Maggio EM, van den Berg A, de Jong D, et al. Low frequency of FAS mutations in Reed-Sternberg cells of Hodgkin's lymphoma. Am J Pathol 2003;162:29-35.

4 Re D, Müschen M, Ahmadi T, et al. Oct-2 and Bob-1 deficiency in Hodgkin and Reed-Sternberg cells. Cancer Res 2001;61:2080-2084.

5 Kanzler H, Küppers R, Hansmann ML, et al. Hodgkin and Reed-Sternberg cells in Hodgkin's disease represent the outgrowth of a dominant tumour clone derived from (crippled) germinal center B cells. J Exp Med 1996;184:1495-1505.

6 Küppers R, Klein U, Hansmann ML, et al. Cellular origin of human B-cell lymphomas. N Engl J Med 1999;341:1520-1529.

7 Theil J, Laumen H, Marafioti T, et al. Defective octamer-dependent transcription is responsible for silenced immunoglobulin transcription in Reed-Sternberg cells. Blood 2001;97:3191-3196.

8 Stein H, Marafioti T, Foss HD, et al. Down-regulation of BOB.1/OBF.1 and Oct2 in classical Hodgkin disease 
but not in lymphocyte predominant Hodgkin disease correlates with immunoglobulin transcription. Blood 2001;97:496-501.

9 Staudt LM, Clerc RG, Singh H, et al. Cloning of a lymphoid-specific cDNA encoding a protein binding the regulatory octamer DNA motif. Science 1988; 241:577-580.

10 Luo Y, Roeder RG. Cloning, functional characterization and mechanism of action of the B-cell-specific transcriptional coactivator OCA-B. Mol Cell Biol 1995;15: 4115-4124.

11 Henderson A, Calame K. Transcriptional regulation during $B$ cell development. Annu Rev Immunol 1998;16:163-200.

12 Sturm RA, Das G, Herr W. The ubiquitous octamerbinding protein Oct-1 contains a POU domain with a homeo box subdomain. Genes Dev 1988;2:1582-1599.

13 Staudt LM, Singh H, Sen R, et al. A lymphoid-specific protein binding to the octamer motif of immunoglobulin genes. Nature 1986;323:640-643.

14 Latchman DS. The Oct-2 transcription factor. Int J Biochem Cell Biol 1996;28:1081-1083.

15 Wirth T, Priess A, Annweiler A, et al. Multiple Oct2 isoforms are generated by alternative splicing. Nucleic Acids Res 1991;19:43-51.

16 Sáez AI, Artiga MJ, Sánchez-Beato M, et al. Analysis of octamer-binding transcriptor factors Oct2 and Oct1 and their coactivator BOB.1/OBF.1 in lymphomas. Mod Pathol 2002;15:211-220.

17 Malone CS, Patrone L, Buchanan KL, et al. An upstream Oct-1 and Oct-2 binding silencer governs B29 (Ig beta) gene expression. J Immunol 2000;164: 2550-2556.

18 Pfisterer P, Konig H, Hess J, et al. CRISP-3, a protein with homology to plant defense proteins, is expressed in mouse B cells under the control of Oct2. Mol Cell Biol 1996;16:6160-6168.

19 Thevenin C, Lucas BP, Kozlow EJ, et al. Cell type- and stage-specific expression of the CD20/B1 antigen correlates with the activity of a diverged octamer DNA motif present in its promoter. J Biol Chem 1993;268:5949-5956.

20 Corcoran LM, Karvelas M. Oct2 is required early in T cell-independent B cell activation for G1 progression and for proliferation. Immunity 1994;1:635-645.

21 Shah PC, Bertolino E, Singh H. Using altered specificity Oct-1 and Oct-2 mutants to analyze the regulation of immunoglobulin gene transcription. EMBO J 1997;16:7105-7117.

22 Luo Y, Fujii H, Gerster T, et al. A novel B cell-derived co activator potentiates the activation of immunoglobulin promoters by octamer-binding transcription factors. Cell 1992;71:231-241.

23 Strubin M, Newell JW, Matthias P. OBF-1, a novel B cell-specific coactivator that stimulates immunoglobulin promoter activity through association with octamer-binding proteins. Cell 1995;80:497-506.

24 Garcia JF, Camacho FI, Morente M, et al, for the Spanish Hodgkin Lymphoma Study Group. Hodgkin and Reed-Sternberg cells harbor alterations in the major tumor suppressor pathways and cell-cycle checkpoints: analyses using tissue microarrays. Blood 2003;101:681-689.

25 Bubendorf L, Nocito A, Moch $\mathrm{H}$, et al. Tissue microarray (TMA) technology: miniaturized pathology archives for high-throughput in situ studies. J Pathol 2001;195:72-79.
26 Harris NL, Jaffe ES, Diebold J, et al. World Health Organization classification of neoplastic diseases of the hematopoietic and lymphoid tissues: report of the Clinical Advisory Committee meeting, Airlie House, VA, November 1997. J Clin Oncol 1999;17: 3835-3849.

27 Morgan J. A protocol for preparing cell suspensions with formalin fixation and paraffin embedding which minimises the formation of cell aggregates. J Cell Pathol 2001;5:171-180.

28 Torlakovic E, Tierens A, Dang HD, et al. The transcription factor PU.1, neccesary for B-cell development is expressed in lymphocyte predominance, but not classical Hodgkin's disease. Am J Pathol 2001;159: 1807-1814.

29 Schwering I, Bräuninger A, Klein U, et al. Loss of the B-lineage-specific gene expression program in Hodgkin and Reed-Sternberg cells of Hodgkin lymphoma. Blood 2003;101:1505-1512.

30 Browne P, Petrosyan K, Hernandez A, et al. The B-cell transcription factors BSAP, Oct-2 and BOB.1 and the pan-B-cell markers CD20, CD22 and CD79a are useful in the differential diagnosis of classic Hodgkin lymphoma. Am J Clin Pathol 2003;120:767-777.

31 Georgopoulos K. Transcription factors required for lymphoid lineage commitment. Curr Opin Immunol 1997;9:222-227.

32 Pileri SA, Gaidano G, Zinzani PL, et al. Primary mediastinal B-cell lymphoma. High frequency of BCL-6 mutations and consistent expression of the transcription factors OCT2, BOB.1 and PU.1 in the absence of immunoglobulins. Am J Pathol 2003; 162:243-253.

33 Steimle-Grauer SA, Tingueley M, Seada L, et al. Expression patterns of transcription factors in progressively transformed germinal centers and Hodgkin lymphoma. Virchows Arch 2003;442: 284-293.

34 Barberis A, Widenhorn K, Vitelli L, et al. A novel Bcell lineage-specific transcription factor present at early but not late stages at differentiation. Genes Dev 1990;4:849-859.

35 Torlakovic E, Torlakovic G, Nguyen PL, et al. The value of anti-pax-5 immunostaining in routinely fixed and paraffin-embedded sections: a novel pan pre-B and B-cell marker. Am J Surg Pathol 2002;26:1343-1350.

36 Foss HD, Reusch R, Demel G, et al. Frequent expression of the B-cell-specific activator protein in ReedSternberg cells of classical Hodgkin's disease provides further evidence for its B-cell origin. Blood 1999;9: 3108-3113.

37 Zhou X, Zhao T, Qi Z, et al. Expression and significance of B-cell-specific activator protein of H/RS cell in classical Hodgkin's lymphoma. Zhonghua Yi Xue Za Zhi 2002;82:1532-1535.

38 Carbone A, Gloghini A, Aldinucci D, et al. Expression pattern of MUM1/IRF4 in the spectrum of pathology of Hodgkin's disease. $\mathrm{Br} \mathrm{J}$ Haematol 2002;117: 366-372.

39 Carbone A, Gloghini A, Cozzi MR, et al. Expression of MUM1/IRF4 selectively clusters with primary effusion lymphoma among lymphomatous effusions. Implications for disease histogenesis and pathogenesis. Br J Haematol 2000;111:247-257.

40 Gaidano G, Carbone A. MUM1: a step ahead toward the understanding of lymphoma histogenesis. Leukemia 2000;14:563-566. 
41 Tsuboi $\mathrm{K}$, Iida $\mathrm{S}$, Inagaki $\mathrm{H}$, et al. MUM1/IRF4 expression as a frequent event in mature lymphoid malignancies. Leukemia 2000;14:449-456.

42 Portis T, Longnecker R. Epstein-Barr virus LMP2A interferes with global transcription factor regulation when expressed during B-lymphocyte development. J Virol 2003;77:105-114.

43 Merchant M, Swart R, Katzman RB, et al. The effects of the Epstein-Barr virus latent membrane protein $2 \mathrm{~A}$ on B cell function. Int Rev Immunol 2001;20:805-835. 